\title{
The Diverging Beliefs and Practices of the Religiously Affiliated and Unaffiliated in the United States
}

\author{
Aaron Gullickson
}

University of Oregon

Abstract: Since 1990, the percentage of Americans with no religious affiliation has grown substantially. Prior work has shown that between 1990 and 2000, the religiously unaffiliated population also became more religious in belief and practices, both in absolute terms and relative to the affiliated population. This curious empirical finding is believed to be driven by a dilution effect in which moderate believers disaffiliated from organized religion without giving up religious beliefs and practices. In the current article, I use data from the General Social Survey to show that this convergence of beliefs and practices of the religiously affiliated and unaffiliated ended around 2000. Since 2000, the religiously unaffiliated have decreased their belief in God and the afterlife and have not increased their prayer frequency. The trends for the affiliated have been either increasing or unchanging, and thus, the religious practices and beliefs of the religiously affiliated and unaffiliated have diverged since 2000. The change in trend for the religiously unaffiliated after 2000 cannot fully be explained by generational succession or the growing percentage of Americans raised without religion. Although the unaffiliated remain very heterogeneous in their beliefs and practices, these results point to a growing religious polarization in the United States.

Keywords: religious change; nones; polarization

Citation: Gullickson, Aaron. 2018. "The Diverging Beliefs and Practices of the Religiously Affiliated and Unaffiliated in the United States." Sociological Science 5: 361-379.

Received: April 23, 2018

Accepted: May 14, 2018

Published: June 21, 2018

Editor(s): Jesper Sørensen, Mario Small

DOI: 10.15195/v5.a16

Copyright: (C) 2018 The Author(s). This open-access article has been published under a Creative Commons Attribution License, which allows unrestricted use, distribution and reproduction, in any form, as long as the original author and source have been credited. (0)(1)

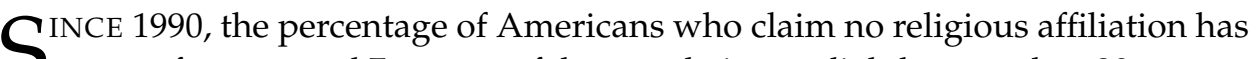
$\mathcal{S}$ grown from around 7 percent of the population to slightly more than 20 percent today (Hout 2017). This unprecedented growth in the religiously unaffiliated has re-ignited academic debates about the exceptional character of American religion and the process of secularization (Hout and Fischer 2002; Marwell and Demerath 2003; Voas and Chaves 2016; Schnabel and Bock 2017). A key question in this debate is the extent to which this rise in nonaffiliation reflects underlying changes in religious beliefs and practices. From a naive point of view (often expressed in popular media), the answer seems obvious: if people are less likely to claim a religious affiliation, they must have lost their faith in God. However, this point of view assumes a congruence between religious identity, beliefs, and practices that is rarely seen in empirical data (Chaves 2010).

In an influential article, Hout and Fischer (2002) showed that the growth of the religiously unaffiliated between 1990 and 2000 was not a function of declines in religious belief or practice. In fact, the religiously unaffiliated increased their belief in God and the the afterlife and prayed more frequently over this time period (2002:173-75). To explain this seeming paradox, Hout and Fischer argue that both cohort change and political polarization drove the most moderate believers away from organized religion, increasing the number of "unchurched believers" among 
the unaffiliated. Because these unchurched believers abandoned their association with organized religion but not necessarily their beliefs and practices, they diluted the more secular views of the unaffiliated population. As a consequence, the affiliated and unaffiliated became more similar rather than less similar in their religious beliefs and practices.

Hout and Fischer (2014) updated and confirmed many of their previous findings (2002) and also presented new evidence pointing to the causal influence of political polarization. However, Hout and Fischer (2014) do not disaggregate the trend in beliefs and practices by religious affiliation or nonaffiliation. Instead, they showed that religious beliefs and practices have changed little for the whole population, and therefore, a loss of religious belief cannot explain the rise of the religiously unaffiliated.

In this article, I use data from the General Social Survey (GSS) to demonstrate that these overall trends in religious beliefs and practices obscure an important divergence between the religiously affiliated and unaffiliated in the new millennium. Since 2000, the religiously unaffiliated have decreased their belief in God and the afterlife and have remained steady in their frequency of prayer. In contrast, the religiously affiliated have increased their belief in the afterlife, remained steady in their belief in God, and prayed more frequently. Therefore, the religious beliefs and practices of the affiliated and unaffiliated have become more dissimilar since 2000. Because these trends have moved in opposite directions, the overall trend has been deceptively flat.

In the following sections, I first lay out the general trends in belief in God, belief in the afterlife, frequency of prayer, and frequency of attendance at religious services. I then explore more closely the specific responses for belief in God and prayer frequency, which are reported in multiple ordinal categories. Finally, I explore how compositional changes in terms of the disaffiliated versus the never affiliated and by birth cohort might explain the trends.

This article provides important new empirical findings on the rise of the religiously unaffiliated in the United States and suggests a revision of our current understanding. I highlight the growing divergence, and therefore polarization, in the beliefs and practices of the religiously affiliated and unaffiliated. Loss of faith cannot logically explain the rise in nonaffiliation because the religious beliefs and practices of the unaffiliated have both risen and fallen over the period in which nonaffiliation has grown steadily. However, the results here suggest that the converse could be true: nonaffiliation with organized religion may ultimately have led to a loss of faith among the unaffiliated. I explore some of these possibilities in the Conclusion.

\section{Data}

Data come from the GSS from 1972 to 2016 . The GSS is a large, nationally representative survey of the U.S. adult population conducted annually or biennially since 1972. All results shown here use sample weights to present results that are representative of the overall U.S. population. 


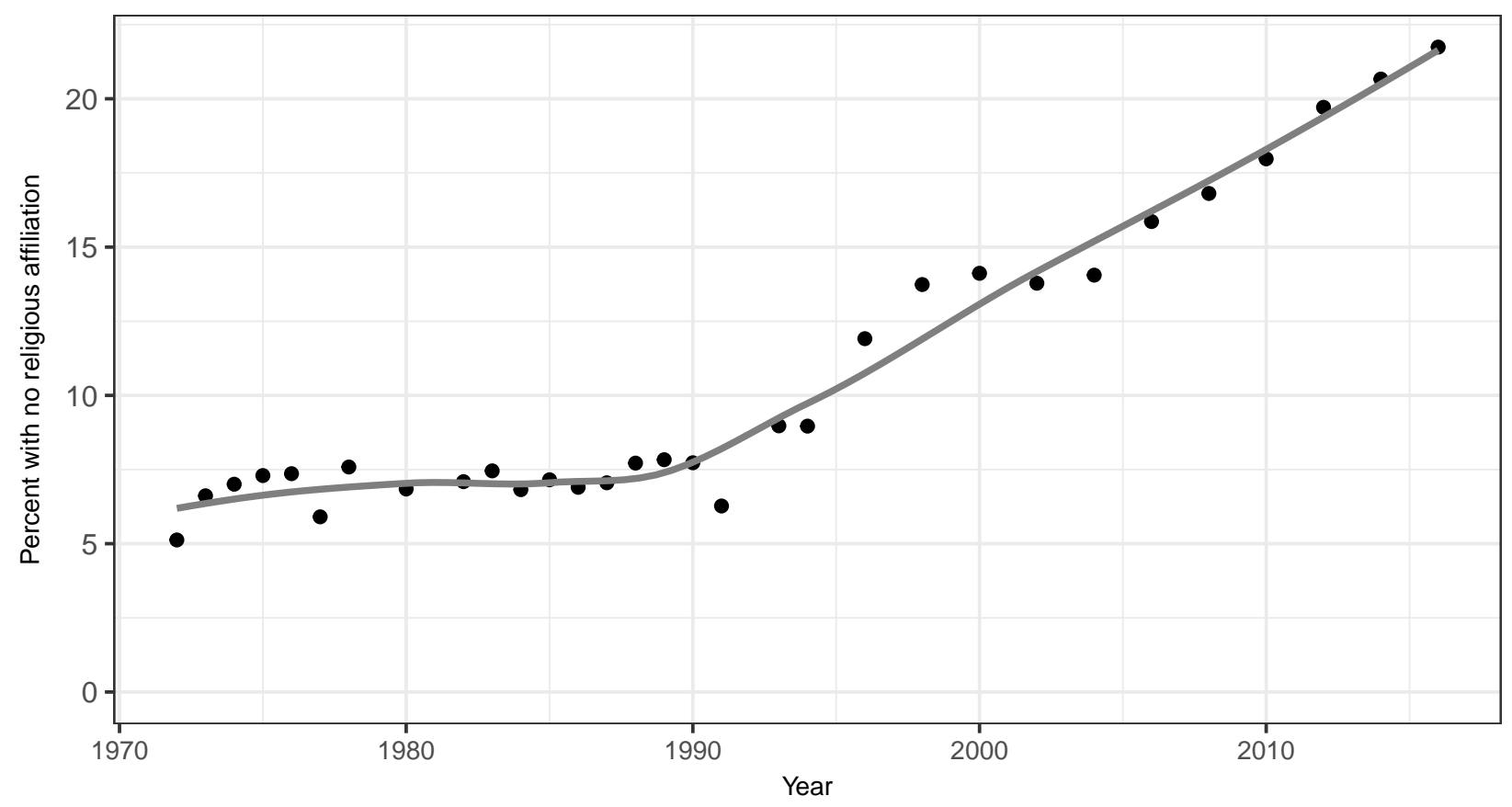

Figure 1: Percentage of respondents in the General Social Survey with no religious affiliation by year. Smoothed trend is shown in grey. All percentages are sample weighted.

Every GSS sample has asked for respondents' religious affiliation and provided "no religion" as a stated option. Consistent with prior work, I define the religiously unaffiliated as individuals who choose "no religion" in response to this question. I also remove the very small number of individuals ( 0.4 percent) who refused the question or reported that they did not know their affiliation. Figure 1 shows the trend over time in the percentage of respondents who identify as unaffiliated. Through 1991, this percentage was stationary across time at about 7 percent of the U.S. adult population. After 1991, there is a steady linear increase in the percentage of respondents who are religiously unaffiliated, reaching nearly 22 percent by the last year of the survey and showing no signs of slowing.

Table 1 shows the four variables used to measure religious beliefs and practices. I use questions about the respondents' belief in God and the afterlife to measure religious beliefs and questions about respondent's frequency of prayer and attendance at religious services to measure practices. The questions vary in how frequently they have been asked on the GSS. The question on attendance has been asked in every year of the GSS, and the afterlife question has been asked in nearly every year since 1973. The questions on prayer and belief in God were added in 1983 and 1988, respectively, and have been excluded from a few years since.

Since 2004, the GSS has included an explicit option of "never" for the question on prayer frequency. Prior to 2004, this option was not provided to respondents but was recorded if volunteered. In order to maintain consistency across years, I have collapsed the "never" and "less than once a week" option across all survey years. 
Table 1: General Social Survey questions about religious beliefs and practices used in the analysis.

God Which statement comes closest to expressing what you believe about God?

(1) I don't believe in God.

(2) I don't know whether there is a God and I don't believe there is any way to find out.

(3) I don't believe in a personal God, but I do believe in a Higher Power of some kind.

(4) I find myself believing in God some of the time, but not at others.

(5) While I have doubts, I feel that I do believe in God.

(6) I know God really exists and I have no doubts about it.

Years asked: 1988, 1991-1994, 1998-2000, 2006-2016

Postlife Do you believe there is a life after death?

(1) No

(2) Don't know

(3) Yes

Years asked: 1973, 1975-1976, 1983-1984, 1986-2016

Pray About how often do you pray?

(1) Less than once a week/Never.

(2) Once a week.

(3) Several times a week.

(4) Once a day.

(5) Several times a day.

Years asked: 1983-1985, 1987-1990, 1993-2016

Attend How often do you attend religious services?

(1) Never

(2) Less than once a year

(3) Several times a year

(4) Once a month

(5) Two or three times a month

(6) Nearly every week

(7) Every week

(8) More than once a week

Years asked: 1972-2016

\section{Overall Trends}

I begin with a simple approach that creates a numeric scale of each ordinal variable that is standardized to have a minimum of zero and a maximum of one. I then calculate the mean of each scale by year and religious affiliation. The results are shown in Figure 2. Smoothed lines are shown for each group, and the overall smoothed trend line for the entire sample is shown as well. All smoothing in this figure and throughout the article is done by locally weighted regression models.

For all variables except attendance, a clear discontinuity in the trends for the unaffiliated is visible around the year 2000. This discontinuity is most visibly salient for belief in the afterlife. From 1973 to 2000, belief in the afterlife increased for both the affiliated and the unaffiliated, but the increase was greater for the unaffiliated, 


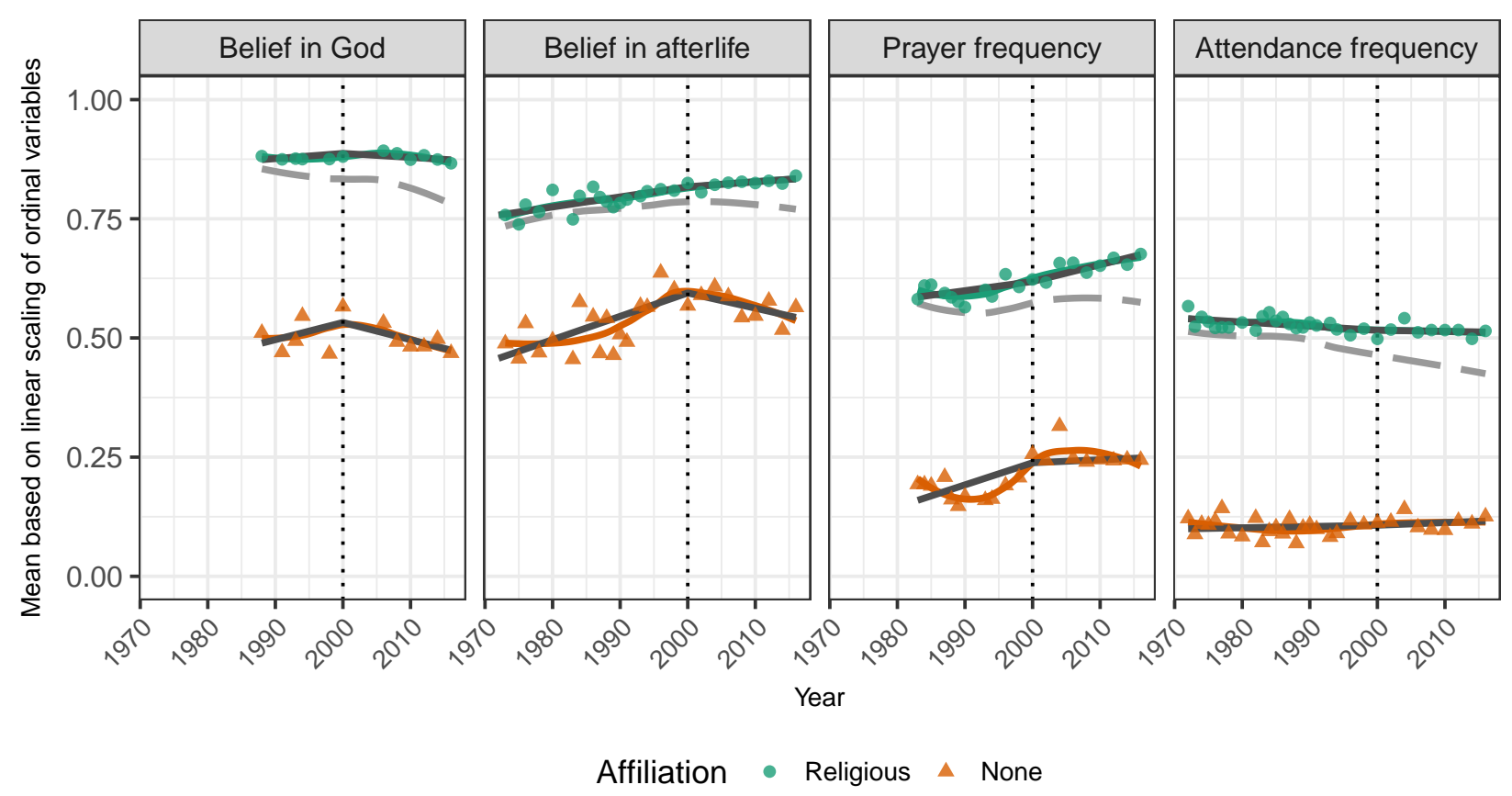

Figure 2: Trends in religious beliefs and practices among the religiously affiliated and unaffiliated from General Social Survey sample data. All ordinal questions are converted to a linear quantitative scale with a maximum of one and a minimum of zero. All means are sample weighted. Smoothed trend lines are shown for each group, and a smoothed trend for all respondents is shown by the light grey, dashed line. The fit of a regression spline model with a hinge at year 2000 is shown in dark grey.

leading to some convergence in beliefs about the afterlife across the two groups. However, around 2000, the trend for the unaffiliated clearly reverses direction, and belief in the afterlife declines among this group. Although belief in the afterlife remains higher among the unaffiliated at the end of the time period than at the beginning, it has clearly declined from its peak values circa 2000. In contrast, belief in the afterlife continued to increase among the affiliated after 2000, leading to a divergence between the two groups and only a slight decline in belief in the afterlife for the entire population.

This same basic pattern also holds for belief in God. In this case, the direction of the trend for the unaffiliated prior to 2000 is less clear because of the shorter time period of observation and sampling error from survey to survey. Nonetheless, the generally downward trend in belief in God among the unaffiliated after 2000 is quite clear. In contrast, belief in God among the affiliated has remained high over the entire time period.

Prayer frequency increased for both groups up to 2000 and continued to increase for the affiliated after 2000. Unlike the two variables measuring beliefs, prayer frequency has not declined among the unaffiliated since 2000 but has remained stationary over time. However, because prayer frequency has increased steadily among the affiliated, the two groups are diverging in their frequency of prayer. The prayer frequency of the entire population has been relatively stationary. 
Attendance is the only variable for which there is no clear discontinuity in trends for the unaffiliated. Both groups have changed little in their frequency of attendance at religious services, although there may be some slight convergence over time as the affiliated decline slightly in religious attendance, whereas the unaffiliated slightly increase. The overall trend in attendance for the entire population has been more sharply negative, but this is entirely due to the growing number of unaffiliated respondents, who have much lower levels of attendance than the affiliated.

To test these relationships more formally, I fit a regression model to each outcome with a spline variable that was "hinged" at 2000. This spline variable allows a linear trend line to vary at a specific point, creating a "hinge" or "broken arrow." The model specification is

$$
y_{i t}=\alpha+\beta x_{i t}+\delta(t-2000)+\gamma s_{t}+\eta(t-2000)\left(x_{i t}\right)+\lambda\left(s_{t}\right)\left(x_{i t}\right),
$$

where $y_{i t}$ is the score on a given outcome for respondent $i$ in year $t, x_{i t}$ is a dummy variable indicating that the respondent has no religious affiliation, and $s_{t}$ is a spline function set to equal zero before the year 2000 and to equal $t-2000$ for the year 2000 onward. Calendar year $t$ is also included as a covariate centered on year 2000 . The $\beta$ parameter gives the difference in the score between those with no affiliation and those with an affiliation in the year 2000. The $\delta$ parameter gives the linear trend for those with a religious affiliation before the year 2000. The $\eta$ parameter gives the difference in this linear trend for the unaffiliated before the year 2000. The dilution hypothesis proposed by Hout and Fischer (2002) expects this term to be positive, indicating a convergence in scores between the affiliated and unaffiliated before 2000. The parameter $\gamma$ for the main effect of the spline term gives the change in the linear trend for those with a religious affiliation after 2000. The parameter $\lambda$ gives the difference in this change in linear trend for the religiously unaffiliated. If there is a divergence between the affiliated and unaffiliated after 2000, then I expect $\lambda$ to be negative.

The fit of these spline models is shown graphically in Figure 2 by the dark grey lines, and the details of the models are shown in Table 2. For ease of interpretation, the calendar year variable has been divided by 10 to give decadal units. The main effects of the year and year-spline variables give the overall trend for the affiliated. The results indicate increasing belief in the afterlife, increasing frequency of prayer, and slight declines in attendance. The main spline effects suggest that for the affiliated after 2000, belief in the afterlife may have increased more slowly, prayer frequency may have increased more quickly, and attendance may have declined more slowly, but none of these changes in trend are statistically significant. Belief in God among the affiliated may have increased up to 2000, with slight declines thereafter, but the changes are quite small.

The interaction between the year and year-spline variables and the no affiliation dummy variable shows the difference in trend for the unaffiliated compared to the affiliated. Before 2000, the unaffiliated increased their beliefs and practices in all four categories faster than the affiliated, as indicated by the positive effects for the year by no affiliation interaction terms. The interaction between the spline and no affiliation provides the change in this effect after 2000. For all outcomes except attendance, the results are strongly negative and larger than the linear trend effects. 
Table 2: Linear regression models predicting strength of belief in God, belief in the afterlife, frequency of prayer, and freqency of attendance at religious services based on General Social Survey data.

\begin{tabular}{lcrrr}
\hline & God & afterlife & prayer & attendance \\
\hline No religious affiliation & $-0.355^{\dagger}$ & $-0.223^{\dagger}$ & $-0.380^{\dagger}$ & $-0.409^{\dagger}$ \\
& $(0.012)$ & $(0.011)$ & $(0.012)$ & $(0.007)$ \\
Decade (year/10) & 0.011 & $0.021^{\dagger}$ & $0.019^{\dagger}$ & $-0.009^{\dagger}$ \\
& $(0.006)$ & $(0.003)$ & $(0.004)$ & $(0.002)$ \\
Decade spline (>2000) & $-0.019^{*}$ & -0.011 & 0.016 & 0.007 \\
& $(0.009)$ & $(0.006)$ & $(0.008)$ & $(0.005)$ \\
Decade x No affiliation & & & & \\
& 0.025 & $0.028^{\dagger}$ & $0.027^{*}$ & $0.011^{*}$ \\
Decade spline x No affiliation & $(0.019)$ & $(0.008)$ & $(0.014)$ & $(0.006)$ \\
& & & & \\
Observations & $-0.053^{*}$ & $-0.070^{\dagger}$ & $-0.056^{*}$ & -0.004 \\
$\mathrm{R}^{2}$ & $(0.027)$ & $(0.017)$ & $(0.023)$ & $(0.012)$ \\
\hline
\end{tabular}

Notes: Standard errors are shown in parentheses. All results use sample weights. Calendar year is centered on $2000 .{ }^{*} p<0.05 ;{ }^{\dagger} p<0.01$.

Before 2000, the affiliated and unaffiliated became more like each other in beliefs and practices. After 2000, the affiliated and unaffiliated became less like each other in beliefs and practices.

The results for all variables are based on a linear scaling of ordinal variables that ignores the actual categorical nature of the response. It is possible that this conceals important information about changes across specific categories of the ordinal variables. In exploratory analysis, I found that results using cumulative logit models for belief in the afterlife were consistent with the results shown here. Until 2000, the percentages of the unaffiliated who either believed in the afterlife or reported that they didn't know both grew in size relative to those who did not believe in the afterlife. After 2000, the percentage who did not believe in the afterlife increased, whereas the percentages in the other two categories declined. ${ }^{1}$ The results for the trends in belief in God and prayer frequency are more complicated. In the next sections, I examine these trends more closely.

\section{Trends in Belief in God}

The distribution of the affiliated across all six categories of belief in God has changed little over time, with a slight increase in the percentage of the affiliated who believe in a nonpersonal "higher power" as opposed to a personal God. Belief in God among the unaffiliated across all six categories has changed substantially, but 

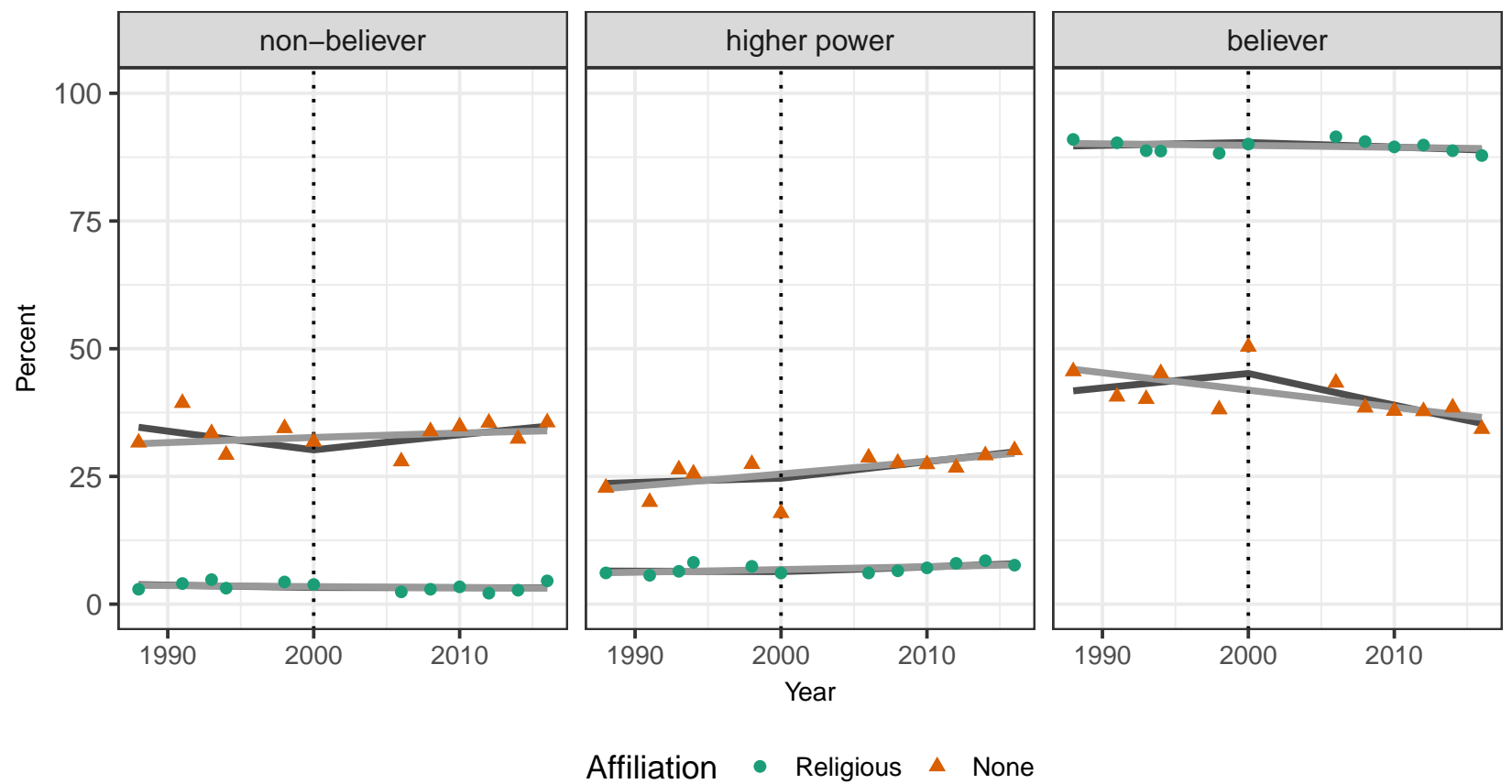

Affiliation - Religious $\Delta$ None

Figure 3: Percentage of General Social Survey respondents in each year who held given beliefs about God by affiliation status. All percentages are sample weighted. The fit of multinomial logit models assuming a linear trend and with a hinge at 2000 are shown in light and dark grey, respectively.

given the relatively smaller numbers of unaffiliated respondents and the number of categories, it is difficult to sort out the trends from statistical noise. Therefore, I have combined these six categories into three larger categories for analysis. ${ }^{2}$ I combine the atheist (don't believe) response and the agnostic (no way to know) response into a single category of "nonbeliever." I combine the three responses indicating varying certainty about a personal God (believe sometimes, believe but doubts, and know God exists) into a single category of "believer." I keep the higher power category separate as an intermediate category between belief in a personal God and nonbelief. As I will show, how one interprets this category has a significant effect on conclusions about the beliefs of the unaffiliated (Marwell and Demerath 2003). Hout and Fischer (2002) consider the higher power category to indicate belief in God and include unaffiliated respondents who choose this response in their "unchurched believer" category. However, this category also explicitly indicates a lack of belief in a personal God and thus seems to be distinct from traditional Western religious practice.

Figure 3 shows the trends in these beliefs among the affiliated and unaffiliated over time. Among the affiliated, there has been little change over time. Around 90 percent of the religiously affiliated express a belief in a personal God. The beliefs of the unaffiliated have changed more significantly. Belief in a personal God has declined over time, balanced by increases in both nonbelief and belief in a nonpersonal higher power. The change in trend before and after 2000 is less visibly clear in this figure than in Figure 2. 
Table 3: Multinomial logit models predicting the level of belief in God based on General Social Survey data.

\begin{tabular}{|c|c|c|c|c|}
\hline & $\begin{array}{l}\text { higher power } \\
\text { vs. nonbelief }\end{array}$ & $\begin{array}{c}\text { believer } \\
\text { vs. nonbelief }\end{array}$ & $\begin{array}{l}\text { higher power } \\
\text { vs. nonbelief }\end{array}$ & $\begin{array}{c}\text { believer } \\
\text { vs. nonbelief }\end{array}$ \\
\hline No religious affiliation & $\begin{array}{r}-0.925^{\dagger} \\
(0.083)\end{array}$ & $\begin{array}{r}-3.013^{\dagger} \\
(0.071)\end{array}$ & $\begin{array}{r}-0.868^{\dagger} \\
(0.167)\end{array}$ & $\begin{array}{r}-2.915^{\dagger} \\
(0.144)\end{array}$ \\
\hline Decade (year/10) & $\begin{array}{c}0.139^{\dagger} \\
(0.052)\end{array}$ & $\begin{array}{c}0.055 \\
(0.043)\end{array}$ & $\begin{array}{c}0.115 \\
(0.168)\end{array}$ & $\begin{array}{c}0.135 \\
(0.138)\end{array}$ \\
\hline Decade spline $(>2000)$ & & & $\begin{array}{c}0.034 \\
(0.258)\end{array}$ & $\begin{array}{c}-0.131 \\
(0.214)\end{array}$ \\
\hline Decade $x$ No affiliation & $\begin{array}{c}-0.071 \\
(0.077)\end{array}$ & $\begin{array}{r}-0.164^{*} \\
(0.066)\end{array}$ & $\begin{array}{c}0.034 \\
(0.260)\end{array}$ & $\begin{array}{c}0.044 \\
(0.222)\end{array}$ \\
\hline Decade spline $x$ No affiliation & & & $\begin{array}{c}-0.154 \\
(0.376)\end{array}$ & $\begin{array}{r}-0.289 \\
(0.323)\end{array}$ \\
\hline
\end{tabular}

Notes: Standard errors are shown in parentheses. All results use sample weights. Base category is no belief. Calendar year is centered on $2000 .{ }^{*} p<0.05 ;{ }^{\dagger} p<0.01$.

In order to explore these trends further, I considered several different statistical models. Cumulative logit models with an assumption of parallel effects across cutpoints (not shown here) did not fit the data well because they failed to estimate the direction of the trend correctly for belief in a higher power among the unaffiliated. I therefore used multinomial models that allow the differences across different categories to vary more freely. ${ }^{3}$ I use the same model framework as before, but I also consider a simpler model with linear trends over time (i.e., no spline effects). The fit of these models is shown in Figure 3, and the models are shown in Table3.

The results from the multinomial models do not provide strong evidence for a change in trend for either group. The spline effect and its interaction with no affiliation are not statistically significant. The model with a simple linear trend for each group is therefore preferred on the grounds of parsimony. This models shows a statistically significant 1.4 percent increase per year in the odds of believing in a higher power rather than nonbelief among the affiliated. The lack of a statistically significant interaction with no affiliation suggests a similar increase for the unaffiliated, although the point estimate is smaller ( 0.7 percent increase per year). The model shows a statistically significant 1.1 percent per year decline in the odds of being a believer versus a nonbeliever among the unaffiliated and little change in these odds over time among the affiliated.

The results indicate that declining belief in a personal God among the unaffiliated has been compensated for by both increases in nonbelief (atheist and agnostic responses) and belief in a nonpersonal higher power. Because belief in a nonpersonal higher power has risen throughout the time period among the unaffiliated, it 

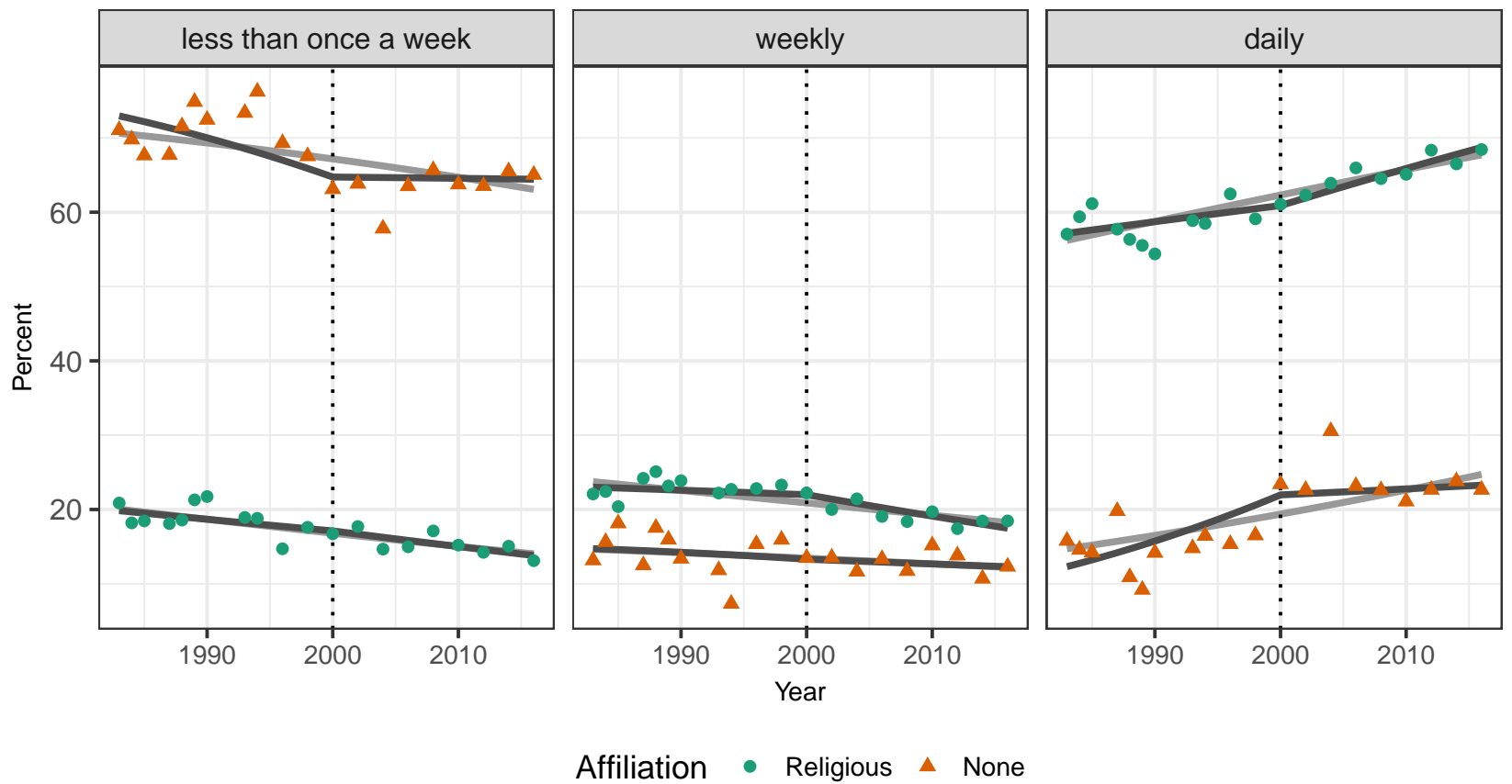

Affiliation - Religious $\Delta$ None

Figure 4: Percentage of General Social Survey respondents in each year who prayed with a certain frequency by affiliation status. All percentages are sample weighted. The fit of multinomial logit models assuming a linear trend and with a hinge at 2000 are shown in light and dark grey, respectively.

may be problematic to assume that belief in God among the unaffiliated is moving in a fully secular direction. Nonetheless, at least since 2000, more secular atheist and agnostic responses appear to be on the rise, and belief in a personal God is on the decline. Thus, on the whole, belief in God has moved away from belief in a personalized deity.

\section{Trends in Prayer Frequency}

I initially ran a cumulative logit model on all five categories of prayer frequency with parallel effects across cutpoints. This model fit reasonably well for the affiliated but fit poorly in some cases for the unaffiliated. In particular, this model failed to capture trends in the "weekly" categories ("once a week" and "several times a week") because these two categories have been on the decline for both the affiliated and unaffiliated throughout the time period. ${ }^{4}$ The frequency of prayer has been polarizing over time into those who pray at least once a day and those who pray less than once a week (including never).

To simplify the analysis, I collapsed the two categories of weekly prayer and the two categories of daily prayer ("once a day" and "several times a day") to create three categories of less than once a week, weekly, and daily prayer. The trends over time for the unaffiliated and affiliated are shown in Figure 4.

As noted above, weekly prayer has been declining from an already low percentage for both the affiliated and unaffiliated. Prior to 2000, daily prayer became more frequent, and praying less than once a week became less frequent for both groups. 
Table 4: Multinomial logit models predicting the frequency of prayer based on General Social Survey data.

\begin{tabular}{|c|c|c|c|c|}
\hline & $\begin{array}{c}\text { weekly } \\
\text { vs. It weekly }\end{array}$ & $\begin{array}{c}\text { daily } \\
\text { vs. lt weekly }\end{array}$ & $\begin{array}{c}\text { weekly } \\
\text { vs. It weekly }\end{array}$ & $\begin{array}{c}\text { daily } \\
\text { vs. It weekly }\end{array}$ \\
\hline No religious affiliation & $\begin{array}{r}-1.826^{\dagger} \\
(0.052)\end{array}$ & $\begin{array}{r}-2.554^{\dagger} \\
(0.046)\end{array}$ & $\begin{array}{r}-1.833^{\dagger} \\
(0.106)\end{array}$ & $\begin{array}{r}-2.350^{\dagger} \\
(0.089)\end{array}$ \\
\hline Decade (year/10) & $\begin{array}{c}0.028 \\
(0.018)\end{array}$ & $\begin{array}{c}0.164^{+} \\
(0.015)\end{array}$ & $\begin{array}{c}0.060 \\
(0.040)\end{array}$ & $\begin{array}{r}0.124^{\dagger} \\
(0.034)\end{array}$ \\
\hline Decade spline $(>2000)$ & & & $\begin{array}{r}-0.070 \\
(0.078)\end{array}$ & $\begin{array}{c}0.086 \\
(0.066)\end{array}$ \\
\hline Decade $x$ No affiliation & $\begin{array}{r}-0.049 \\
(0.048)\end{array}$ & $\begin{array}{c}0.027 \\
(0.042)\end{array}$ & $\begin{array}{r}-0.050 \\
(0.116)\end{array}$ & $\begin{array}{r}0.287^{+} \\
(0.109)\end{array}$ \\
\hline Decade spline $x$ No affiliation & & & $\begin{array}{c}0.013 \\
(0.199)\end{array}$ & $\begin{array}{r}-0.458^{\dagger} \\
(0.173)\end{array}$ \\
\hline
\end{tabular}

Notes: Standard errors are shown in parentheses. All results use sample weights. Base category is praying less than once a week. Calendar year is centered on 2000. 1 t, one time. ${ }^{*} p<0.05{ }^{\dagger} p<0.01$.

However, after 2000, there is some indication that these trends plateaued for the unaffiliated. To test this pattern more formally, I ran two multinomial models with praying less than once a week as the baseline category. The results are shown in Table 4, and the fit of these models is shown in Figure 4. These models are identical in form to those for belief in God. I find small and negligible effects in both models and across all variables when comparing weekly to less-than-weekly prayer. The important differences emerge in the comparison between daily and less-than-weekly prayer. I first test a simple linear trend for both groups and find that according to this model, the frequency of daily prayer increased at the same pace for both groups relative to less-than-weekly prayer. However, in the second model, I test a change in this linear trend after 2000. According to this model, before 2000, the odds of daily versus less-than-weekly prayer increased by about 1.2 percent per year for the affiliated and by about 4.1 percent per year for the unaffiliated, leading to some convergence in the frequency of prayer between these groups. However, after 2000, that increase became somewhat larger for the affiliated (2.1 percent per year), whereas the rate of increase for the unaffiliated is close to zero (0.4 percent per year), leading to a divergence in the frequency of prayer between these groups. Thus, these results largely confirm the results by using linear scaling from Figure 2 and Table 2 but point to the distinction between those who pray daily and all other categories of prayer frequency as the important dividing line. 


\section{Changes in Belief or Personnel?}

The decline in religious beliefs and practices among the unaffiliated after 2000 may reflect actual changes in the beliefs and practices of individuals with no religious affiliation, or it may reflect compositional changes in who constitutes the unaffiliated population. Given the rapid growth of this population, compositional changes may be important. There are two compositional changes that I consider here. First, one can separate the unaffiliated into those who disaffiliated from a religious background and those who were never affiliated in the first place. Second, cohort replacement has been an important driver of the growth in the unaffiliated and may also play a role in changes in the beliefs and practices among this group.

\section{The Disaffiliated versus Never Affiliated}

Since 1973, the GSS has asked respondents about their religious affiliation at age 16. Individuals who indicated a religious affiliation at age 16 but who are unaffiliated currently can be considered as those who disaffiliated from the religion of their upbringing. Individuals who indicated no affiliation at age 16 and no affiliation currently can be considered those who were never affiliated. The percentage of respondents who were raised with no religious affiliation has grown rapidly among birth cohorts born since 1960 (Schwadel 2010). Because religion was less important in their upbringing, the never affiliated may have weaker religious beliefs and practices than the disaffiliated. If the never affiliated became a larger share of the unaffiliated population over this time period, then this change in composition may have driven some of the observed changes in trends.

Figure 5 shows the percentage of never-affiliated and disaffiliated respondents in each year of the GSS. Contrary to expectation, the never affiliated have not consistently grown as a share of the unaffiliated population. In fact, the greatest growth in the never affiliated relative to the disaffiliated occurred prior to 2000 . After 2000, the percentage of respondents who were never affiliated leveled off, whereas the percent who were disaffiliated grew substantially. ${ }^{5}$

Because the never affiliated actually became a relatively smaller share of the unaffiliated population after 2000, it is unlikely that this compositional change can explain the changing trends in beliefs and practices among the unaffiliated. Nonetheless, Figure 6 explores differences in beliefs and practices between the never affiliated and the disaffiliated. This figure shows the average value for each group using the same linear scaling as Figure 2 but splits the unaffiliated into the two subgroups of never affiliated and disaffiliated.

The never affiliated do not seem to differ from the disaffiliated in their beliefs about God and the afterlife. Apart from the greater sampling error year to year, the never affiliated tend to have the same level of belief, and the trends over time are very similar. However, the never affiliated do differ in their frequency of religious practices. In both the case of prayer and attendance, the never affiliated have a lower frequency than the disaffiliated. Therefore, what seems to differentiate these groups is not belief but rather a taste for certain religious practices. Unsurprisingly, those raised in a religious home have a greater taste for continuing their religious practices even after disaffiliation. These results clearly demonstrate that compositional 


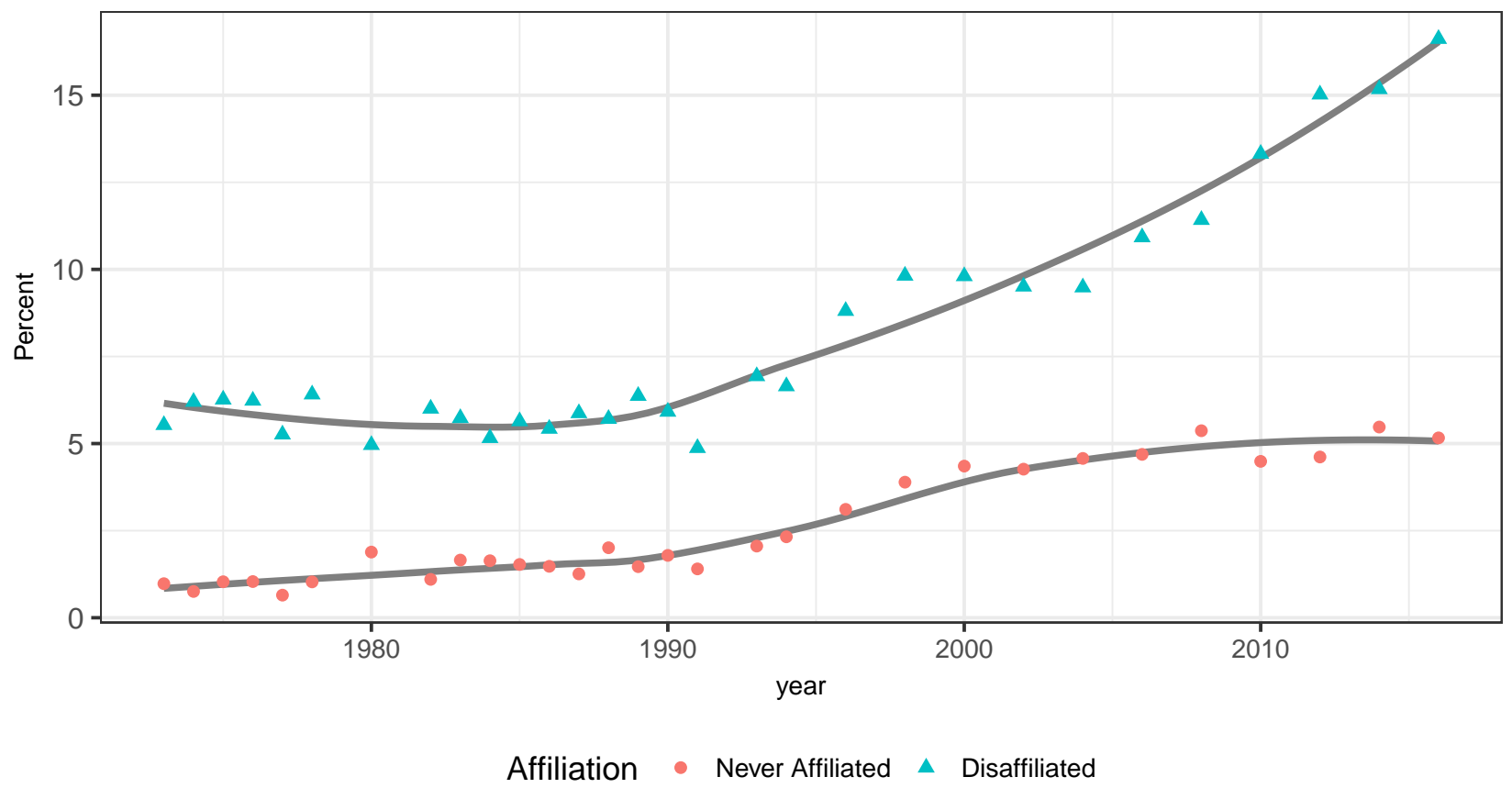

Figure 5: Percentage of respondents in the General Social Survey who dissafiliated from religion and who were never affiliated with religion by year. Smoothed trends are shown in grey. All percentages are sample weighted.

change between the disaffiliated and never affiliated over time cannot explain the change in trends observed after 2000 because the levels and trends for both groups are quite similar.

\section{Cohort Change}

The growth in the unaffiliated has been driven disproportionately by younger birth cohorts. About two-thirds of the growth in the unaffiliated can be attributed to cohort change (Hout and Fischer 2014: 428). Furthermore, these cohort effects were particularly strong for the baby boomer cohorts, who came of age in the 1960s (Schwadel 2010). Hout and Fischer (2002) suggest that the rise in religious nonaffiliation may be a legacy of the social disruption of the 1960s, which caused many to turn away from organized religion. If this is true, then we would expect that cohorts who came of age during this time period may continue to hold more religious beliefs and practices than those who came before and after. This could account for the nonlinear trend we observe in Figure 2. We would see a rise in beliefs and practices in the 1990s as these cohorts begin to dominate the group and then a decline or leveling off as later cohorts enter the population.

Cohort analysis of these data is complicated by the relatively small sample size of unaffiliated respondents within each calendar year and birth cohort. I first conducted an exploratory analysis by disaggregating results by period, 10-year birth cohort, and affiliation for the scalar variables measuring belief in God, belief in the afterlife, and frequency of prayer. Although there is considerable noise, these 


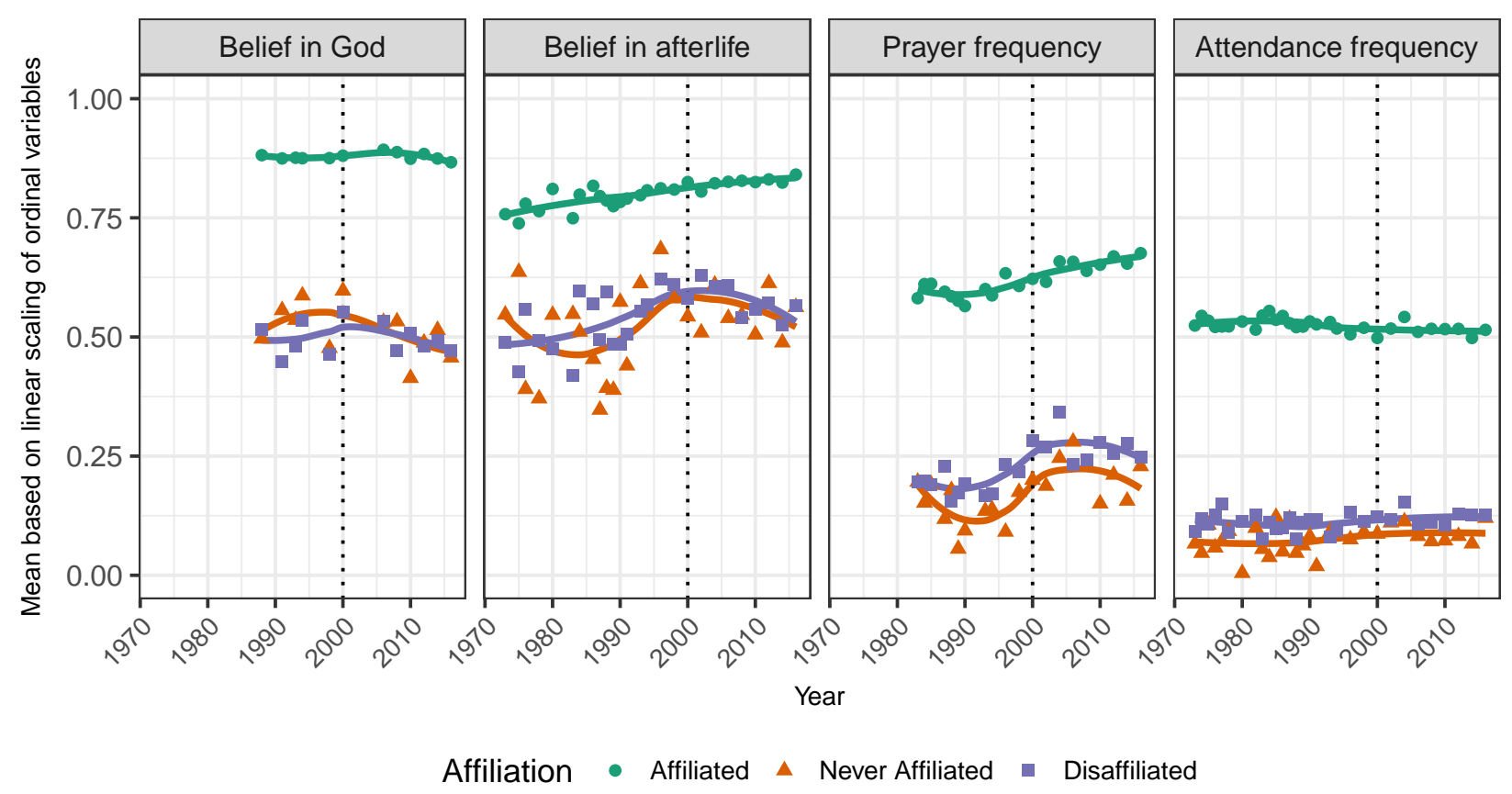

Figure 6: Trends in religious beliefs and practices among the religiously affiliated, the disaffiliated, and the never affiliated in the General Social Survey. All ordinal questions are treated as a linear quantitative scale with a maximum of one and a minimum of zero. All means are sample weighted. Smoothed trend lines are shown for each group.

results suggest similarities by cohort for the unaffiliated in three distinct groups: those born before 1950, those born between 1950 and 1979, and those born after 1980. The middle group is broader than what is generally considered to be the baby boomer cohorts, but the exploratory analysis found similar trends across all three decadal birth cohorts within this group. ${ }^{6}$

Figure 7 shows the trends for each of these birth cohort groups disaggregated by affiliation. Smoothed lines are also shown for each cohort group. ${ }^{7}$ The top three panels show the trends for the religiously affiliated. There is little evidence of cohort differences in belief in God or the afterlife among the affiliated except for a slight decline in belief in God among those born after 1979. There is some evidence of a cohort decline in the frequency of prayer among the affiliated, but this cohort difference has converged over time for the two older cohorts, suggesting that age may play some role as well.

Among the unaffiliated, cohort trends for belief in God provide the strongest evidence that cohort change may play some role in the overall trends. Unaffiliated respondents from cohorts born before 1950 and after 1979 have substantially lower levels of belief in God than those from cohorts born between 1950 and 1979. However, after 2000, there appears to be some within-cohort decline for all three cohort groups.

Unaffiliated members of the 1950-to-1979 birth cohorts are are also much more likely to believe in an afterlife than those in the cohorts born before 1950. Thus, the unaffiliated in the baby boomer cohorts seem to have substantially stronger 


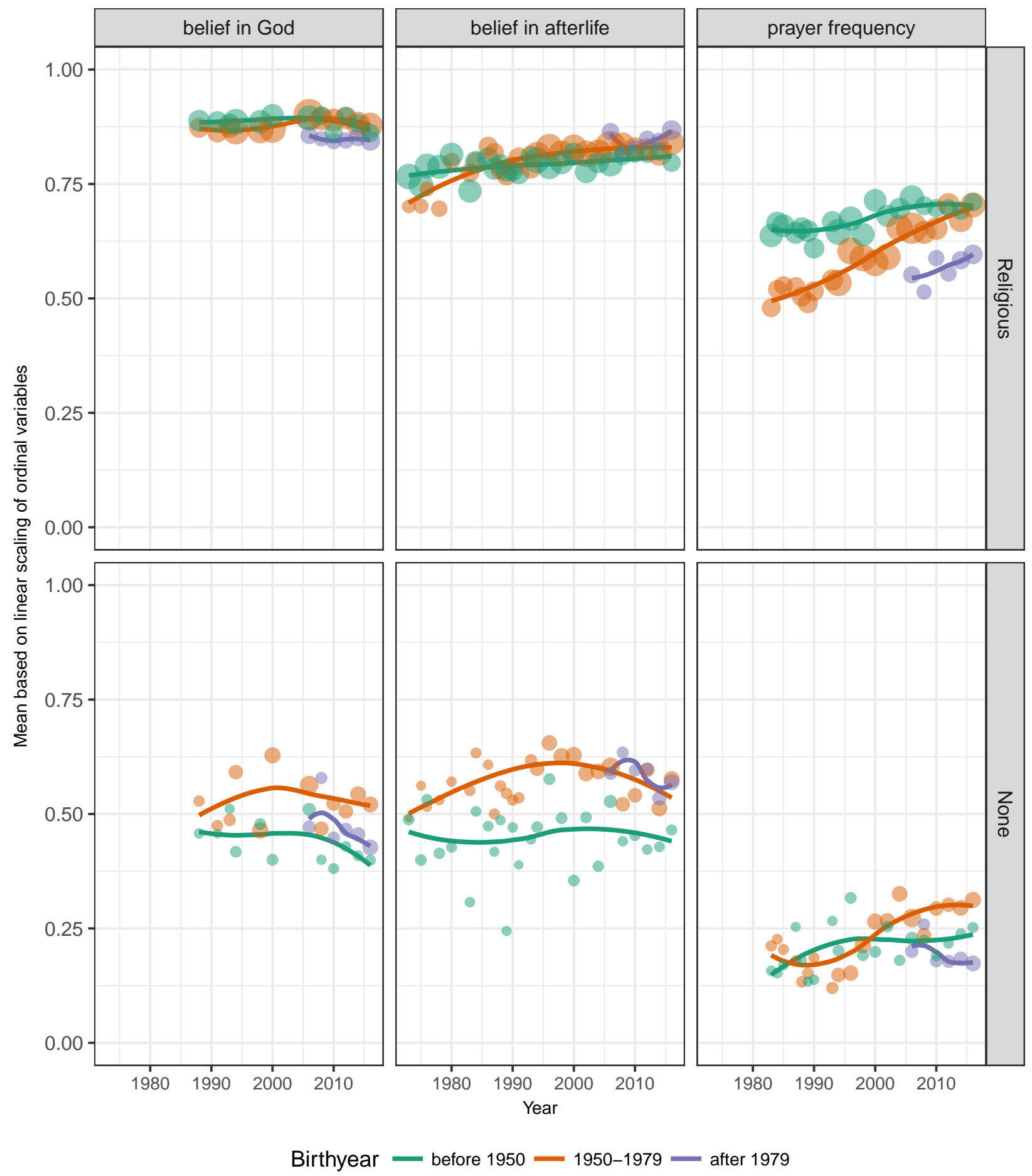

Figure 7: Trends in religious beliefs and practices disaggregated by affiliation status and birth cohort. All ordinal questions are treated as a linear quantitative scale with a maximum of one and a minimum of zero. All means are sample weighted. Smoothed trend lines are shown for each group. Point size is scaled by sample size. 
religious beliefs than the unaffiliated from earlier cohorts. However, the latest cohorts born since 1979 have similar levels of belief in the afterlife to those born between 1950 and 1979. Although the percentage who believe in the afterlife among the pre-1950 birth cohort has remained the same over time, there is a clear rise and fall of belief in the afterlife for the 1950-to-1979 birth cohort that mirrors the overall trend. Thus, these cohort patterns cannot fully account for the trend in belief in the afterlife among the unaffiliated.

Until the mid-1990s, the unaffiliated in the cohorts born between 1950 and 1979 prayed about as frequently as those born before 1950, but after the mid-1990s, prayer frequency in this group went up considerably before leveling off by the mid2000s, whereas it remained stationary or rose slightly for the pre-1950 cohorts. The unaffiliated born after 1979 have a lower prayer frequency than either of the other two cohorts. As for belief in the afterlife, within-cohort change in the 1950-to-1979 birth cohort that mirrors the overall trend suggests that something more than cohort change is responsible for the overall trend.

\section{Conclusions}

The foregoing analysis looked at trends in the religious beliefs and practices of the religiously unaffiliated. Prior work has argued that the growth in the unaffiliated has been driven in part by "unchurched believers" who are abandoning their affiliation with organized religion but not necessarily their religious beliefs and practices. Ironically, these unchurched believers may have diluted the nonreligious attitudes of the religiously unaffiliated and made the affiliated and unaffiliated more like one another in their beliefs and practices. Consistent with prior work, I find evidence of such dilution in the period before 2000. In this period, belief in the afterlife and the frequency of prayer increased among the unaffiliated at a faster rate than among the affiliated. Overall levels of belief in God increased among the unaffiliated as well but largely through increasing belief in a nonpersonal higher power. Belief in a personal God appears to have declined steadily over time among the unaffiliated.

After 2000, all these trends either reverse or stagnate. The unaffiliated believe in God and the afterlife less today than in 2000 and pray with the same frequency as in 2000. These trends run counter to the trends for the affiliated, and therefore, since 2000, the affiliated and unaffiliated have become more unlike each other in their beliefs and practices. Nonaffiliation is today more predictive of a person's beliefs and practices than it was in 2000. The diluting effect of unchurched believers appears to have been a fleeting phenomenon.

An increase in the number of individuals who have never been affiliated with religion cannot explain the change in the trend for the unaffiliated. Those who have never been affiliated practice religion less frequently in terms of prayer and attendance at religious services than the disaffiliated but hold beliefs about God and the afterlife that are similar. Additionally, the trend over time is identical for both the never affiliated and the disaffiliated across all four measures of beliefs and practices. 
Cohort replacement may explain some but not all of the change in trends for the unaffiliated. The unaffiliated in those cohorts born between 1950 and 1979 have considerably more religious beliefs than the cohorts that came before. They also have have a stronger belief in God than the unaffiliated from cohorts that came later. However, although the beliefs and practices of cohorts born before 1950 have been relatively stationary, there have been increases and declines within the other two cohort groups that correspond to the overall trend. This suggests that something more than cohort replacement is occurring as well.

There are reasons to think that the rising percentage of individuals with no religious affiliation may itself contribute to declines in religious beliefs and practices among this group. Two different mechanisms may be at work here. First, the social networks of the unaffiliated may include more similarly unaffiliated individuals. The increasing homogeneity of these networks could be driven both by the growth of the unaffiliated and homophily of characteristics related to nonaffiliation, such as occupation, age, and education. Such network homogeneity can potentially drive group polarization and changing values and beliefs (Myers and Lamm 1976; Baldassarri and Bearman 2007). Second, the growth of the unaffiliated has provided an opportunity to create collective organizations and movements around secular points of view. The 2000s saw the creation of a secular movement centered around "new atheist" personalities such as Sam Harris, Richard Dawkins, and Christopher Hitchens (Cimino and Smith 2011). This movement grew from an online presence that was not possible in earlier periods but also because of the growth of a potential audience open to its ideas.

These results are consistent with claims that suggest that growing polarization rather than secularization characterizes the changing religious landscape in the United States (Hout and Fischer 2014; Schnabel and Bock 2017). Even as the religious beliefs and practices of the unaffiliated declined, those of the affiliated strengthened or remained steady. Because the unaffiliated have grown relative to the affiliated, the overall trend in religious beliefs and practices is slightly downward in most cases. However, this slight downward trend in the total population hides the much more substantial shifts in beliefs and practices among the affiliated and unaffiliated.

Although the current trends suggest that the religious beliefs and practices of the unaffiliated are becoming more congruent with what one would expect of a secular population, I do not wish to overstate the degree of this congruence or suggest that the unaffiliated constitute a clear atheist or even secular identity. In comparison to the affiliated, the beliefs of the unaffiliated are still extremely heterogeneous. More than 50 percent still believe in an afterlife, and the modal category of belief in God is belief in a nonpersonal higher power. The unaffiliated include individuals with a wide variety of beliefs and practices outside the norm of traditional organized religion. Such heterogeneity should be expected of a population identified by its denial rather than assertion of a specific religious identity. Nonetheless, since 2000, this population has grown relatively more secular in its beliefs and practices. If this population continues to grow in relative size and become more secular in its beliefs and practices, it will drive overall declines in religiosity as well as greater polarization. 


\section{Notes}

1 Results of this analysis are shown in the supplementary material.

2 A full description of the trends across all six categories is available in the supplementary material.

3 It is also possible to estimate cumulative logit models with nonparallel effects across cutpoints, however, the fit of these models is virtually identical to multinomial models but somewhat more difficult to interpret.

4 These results are available in the supplementary material.

5 It is beyond the scope of this article to account for these trends fully. Exploratory analysis indicated that the plateauing of the percentage of never affiliated is driven by a similar trend in the percentage of respondents who report being raised without religious affiliation by period even as this percentage has grown by birth cohort. Therefore, the trend here is likely driven by a complex relationship between cohort and period trends and not by a change in conversion rates among the never affiliated.

6 This exploratory analysis is available in the supplementary material.

7 I only look at data points from 2005 onward for the youngest cohort born after 1979 because relatively few members of this cohort are in the survey in earlier years, leading to substantial noise.

\section{References}

Baldassarri, Delia, and Peter Bearman. 2007. "Dynamics of Political Polarization." American Sociological Review 72:784-811. https : //doi.org/10.1177/000312240707200507.

Chaves, Mark. 2010. "Rain Dances in the Dry Season: Overcoming the Religious Congruence Fallacy." Journal for the Scientific Study of Religion 49:1-14. https : //doi .org/10.1111/j . 1468-5906.2009.01489.x.

Cimino, Richard, and Christopher Smith. 2011. "The New Atheism and the Formation of the Imagined Secularist Community." Journal of Media and Religion 10:24-38. https : //doi.org/10.1080/15348423.2011.549391.

Hout, Michael. 2017. "American Religion, All or Nothing at All." Contexts 16:78-80. https : //doi.org/10.1177/1536504217742401.

Hout, Michael, and Claude S. Fischer. 2002. "Why More Americans Have No Religious Preference: Politics and Generations." American Sociological Review 67:165-90. https: //doi.org/10.2307/3088891.

Hout, Michael, and Claude S. Fischer. 2014. "Explaining Why More Americans Have No Religious Preference: Political Backlash and Generational Succession, 1987-2012." Sociological Science 1:423-47. https : //doi .org/10.15195/v1.a24.

Marwell, Gerald, and N. J. Demerath. 2003. "'Secularization' by Any Other Name." American Sociological Review 68:314-16. https: //doi .org/10.2307/1519771.

Myers, David G., and Helmut Lamm. 1976. "The Group Polarization Phenomenon." The Psychological Bulletin 83:602-27. https://doi .org/10.1037/0033-2909.83.4.602. 
Schnabel, Landon, and Sean Bock. 2017. "The Persistent and Exceptional Intensity of American Religion: A Response to Recent Research." Sociological Science 4:686-700. https://doi.org/10.15195/v4.a28.

Schwadel, Philip. 2010. "Period and Cohort Effects on Religious Nonaffiliation and Religious Disaffiliation: A Research Note." Journal for the Scientific Study of Religion 49:311-19. https://doi.org/10.1111/j.1468-5906.2010.01511.x.

Voas, David, and Mark Chaves. 2016. "Is the United States a Counterexample to the Secularization Thesis?" American Journal of Sociology 121:1517-56. https://doi .org/10.1086/ 684202.

Acknowledgements: I would like to thank Michael Hout and Claude Fischer for comments on early drafts of this article. Direct all correspondence to aarong@uoregon.edu. All code and data used to conduct this analysis as well as supplementary material is available at https://osf .io/94kv6/.

Aaron Gullickson: Department of Sociology, University of Oregon.

E-mail: aarong@uoregon.edu. 